\title{
Impact of post-dilatation on strut apposition of second-generation bioresorbable vascular scaffolds: Key role for scaffold thrombosis and prognosis?
}

\author{
Antonio H. Frangieh ${ }^{1 *}$, Milosz Jaguszewski ${ }^{1,2,3}$, Yoichi Imori ${ }^{1}$, \\ Slayman Obeid ${ }^{1}$, Christian Templin ${ }^{1}$ \\ ${ }^{1}$ University Hospital Zurich, University Heart Center, Zurich, Switzerland \\ ${ }^{2}$ First Department of Cardiology, Medical University of Gdansk, Poland \\ ${ }^{3}$ Institute of Cardiovascular Translational Research of the Atlantic, Spain
}

This paper was guest edited by Prof. Marek Koziński

A 54-year-old patient, with known history of type 1 diabetes mellitus and hypercholesterolemia had been referred to the documented center due to subacute non-ST segment elevation myocardial infarction. Coronary angiography revealed a highgrade unstable and calcified lesion in the middle portion of the right coronary artery considered as a culprit lesion (Fig. 1A). The lesion preparation was achieved using a $2.5 \times 15 \mathrm{~mm}$ compliant balloon inflated up to 14 atmospheres (atm), then a $3.0 \times 15 \mathrm{~mm}$ non-compliant balloon inflated up to $18 \mathrm{~atm}(3.12 \mathrm{~mm})$; subsequently, a second-generation everolimus-eluting bioresorbable vascular scaffold $\left(\mathrm{BVS}, \mathrm{ABSORB}^{\mathrm{TM}} 3.0 \times 18 \mathrm{~mm}\right.$, Abbott Vascular, Santa Clara CA, USA) was deployed progressively up to $11 \mathrm{~atm}(3.24 \mathrm{~mm})$. Optical frequency-domain imaging (OFDI, Ilumien Optis System from St. Jude Medical, Inc. St. Paul, MN, USA) were utilized to assess the strut apposition inapparent in coronary angiography (Fig. 1B-D). Overall, 183 cross-sections were evaluated during three OFDI-pullbacks ( $n=1615$ struts). Struts were malapposed when the distance of the adluminal strut reflection from the vessel wall exceeded half of the nominal strut thickness (75 out of $150 \mu \mathrm{m}$ ). Strut malapposition of $13.02 \%$ ( $\mathrm{n}=74 / 560)$ was documented directly after BVS implantation (Fig. 1B, E), 8.70\% $(\mathrm{n}=46 / 529)$ after several post-dilatations with a $3.0 \times 12 \mathrm{~mm}$ non-compliant balloon inflated up to $24 \mathrm{~atm}(3.20 \mathrm{~mm}$ ) (Fig. 1C, F) and $6.10 \%$ (n $=32 / 525)$ after an additional two post-dilatations with a $3.5 \times 15 \mathrm{~mm}$ non-compliant balloon inflated up to $14 \mathrm{~atm}$ (3.54 mm) (Fig. 1D, G).

This example case illustrates some important procedural techniques for optimal implantation of a BVS. A 1:1 balloon:vessel pre-dilatation was achieved $(3.12 \mathrm{~mm}$ for a $3.0 \mathrm{~mm}$ BVS). Post-dilatation with a non-compliant balloon was performed afterwards and inflated $0.5 \mathrm{~mm}$ over the nominal diameter of the scaffold. Since BVS implant is radiolucent, additional intracoronary imaging modalities i.e. OFDI are valuable to guide optimal BVS-strut apposition [1-3], which was very well demonstrated in this case, especially that post-dilatation strategies were oriented based on struts malapposition observed on OFDI consecutive pullbacks. It was observed that strut apposition significantly improved after further post-dilatations with higher pressure balloons $(13.02 \%, 8.70 \%$ to $6.10 \%$ progressively). At 30-days follow-up, the patient evolution was smooth and free of cardiovascular event.

The in-scaffold thrombosis is a major concern following BVS-implantation [4]. The impact of stent apposition and strut characteristics on the neointimal healing process and subsequent stent thrombosis are clearly demonstrated [5]. The importance of pre and post-dilatation in optimizing scaffold implantation and expansion should not be underestimated, particularly in the case of complex lesions

Address for correspondence: Prof. Christian Templin, MD, PhD, FESC, University Hospital Zurich, Cardiology, Cardiovascular Center, Raemistr. 100, 8091 Zurich, Switzerland, tel: +41 (0)44 255 9585, fax: +41 (0)44 2554401 , e-mail: Christian.Templin@usz.ch

Received: 05.12.2016 Accepted: 12.11.2017

*Dr Frangieh's current employer is the German Heart Center - Munich, Germany. 


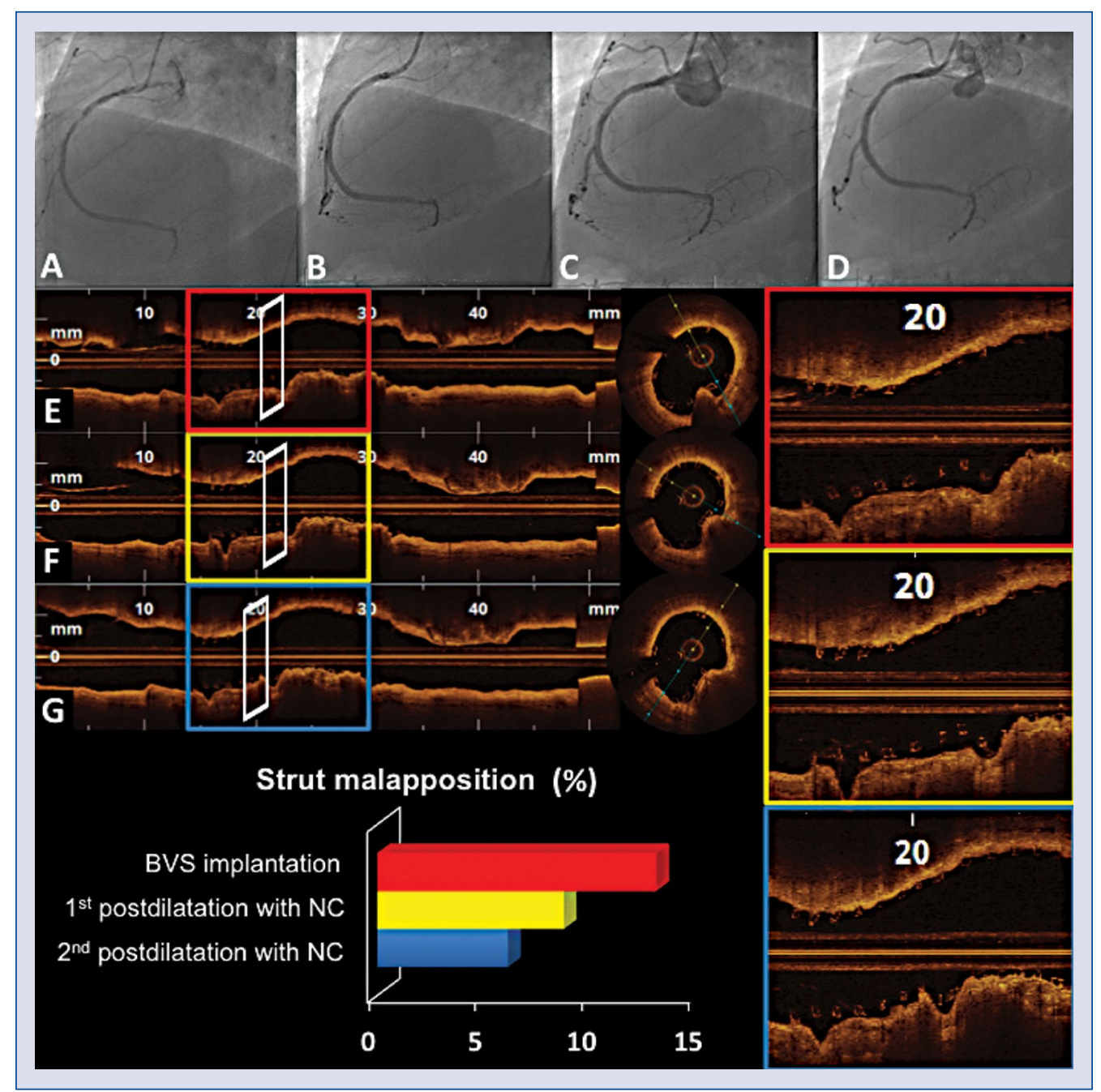

Figure 1. Serial right coronary artery angiography images (A-D) and correspondent optical frequency-domain imaging consecutive pullbacks (E-G). Panel A shows the culprit lesion of the right coronary artery. Panels B, E and the red squares show the results after bioresorbable vascular scaffold (BVS) implantation with $13.02 \%$ of strut malapposition. Panels C, F and the yellow squares show the results after the first postdilatation with a $3.0 \times 12 \mathrm{~mm}$ non-compliant balloon with $8.70 \%$ of strut malapposition. Panels D, G and the blue squares show the final result after additional postdilatation with a $3.5 \times 15 \mathrm{~mm}$ non-compliant balloon with $6.1 \%$ of residual strut malapposition; NC - non-compliant balloon.

(i.e. bifurcations, long lesions, calcified plaques and acute coronary syndromes) [6] where BVS underexpansion, and malapposition are considered main pathomechanisms for both sub-acute or late thrombotic events [7, 8]. Additionally, post-dilatation after a BVS implantation seems to be beneficial even for soft lesions $[9,10]$. On the other hand, it should be emphasized that balloon post-dilatation could result in BVS edge dissection or de-novo stenosis in case of "geographical miss" when the balloon markers are outside the scaffold markers during post-dilatation. Moreover, overexpansion of the scaffold could be also harmful and may result in strut fracture [11] or vessel perforation.
When reviewing the previous publications on BVS, we observe a fluctuation of post-dilatation rate, going from only $14 \%$ of cases in some series [12] to more than $60 \%[4,13]$ and even up to $90 \%$ in other series [14].

Concerns about in-stent thrombosis exist and meticulous procedural techniques application i.e. pre and postdilatation as well as imaging guided percutaneous coronary intervention to optimize struts apposition may be beneficial in order to diminish this risk. Further studies are needed to better clarify this issue.

Conflict of interest: None declared 


\section{References}

1. Gomez-Lara J, Radu M, Brugaletta S, et al. Serial analysis of the malapposed and uncovered struts of the new generation of everolimus-eluting bioresorbable scaffold with optical coherence tomography. JACC Cardiovasc Interv. 2011; 4(9): 992-1001, doi: 10.1016/j.jcin.2011.03.020, indexed in Pubmed: 21939939.

2. Mattesini A, Secco GG, Dall'Ara G, et al. ABSORB biodegradable stents versus second-generation metal stents: a comparison study of 100 complex lesions treated under OCT guidance. JACC Cardiovasc Interv. 2014; 7(7): 741-750, doi: 10.1016/j. jcin.2014.01.165, indexed in Pubmed: 25060016.

3. Jaguszewski M, Ghadri JR, Zipponi M, et al. Feasibility of secondgeneration bioresorbable vascular scaffold implantation in complex anatomical and clinical scenarios. Clin Res Cardiol. 2015; 104(2): 124-135, doi: 10.1007/s00392-014-0757-4, indexed in Pubmed: 25173111.

4. Capodanno D, Gori T, Nef H, et al. Percutaneous coronary intervention with everolimus-eluting bioresorbable vascular scaffolds in routine clinical practice: early and midterm outcomes from the European multicentre GHOST-EU registry. EuroIntervention. 2015; 10(10): 1144-1153, doi: 10.4244/EIJY14M07_11, indexed in Pubmed: 25042421.

5. Lee R, Foin N, Ng J, et al. Early coverage of drug-eluting stents analysed by optical coherence tomography: evidence of the impact of stent apposition and strut characteristics on the neointimal healing process. EuroIntervention. 2016; 12(5): e605-e614, doi: 10.4244/EIJV12I5A100, indexed in Pubmed: 27497360.

6. Imori Y, D'Ascenzo F, Gori T, et al. Impact of postdilatation on performance of bioresorbable vascular scaffolds in patients with acute coronary syndrome compared with everolimus-eluting stents: A propensity score-matched analysis from a multicenter "real-world" registry. Cardiol J. 2016; 23(4): 374-383, doi: 10.5603/CJ.a2016.0052, indexed in Pubmed: 27515481.

7. Karanasos A, Van Mieghem N, van Ditzhuijzen N, et al. Angiographic and optical coherence tomography insights into bioresorbable scaffold thrombosis: single-center experience. Circ Cardiovasc Interv. 2015; 8(5), doi: 10.1161/CIRCINTERVENTIONS.114.002369, indexed in Pubmed: 25969547.
8. Sotomi Y, Suwannasom P, Serruys PW, et al. Possible mechanical causes of scaffold thrombosis: insights from case reports with intracoronary imaging. EuroIntervention. 2017; 12(14): 1747-1756, doi: 10.4244/EIJ-D-16-00471, indexed in Pubmed: 27773862.

9. Naganuma T, Latib A, Panoulas VF, et al. Why do we need post-dilation after implantation of a bioresorbable vascular scaffold even for a soft lesion? JACC Cardiovasc Interv. 2014; 7(9): 1070-1072, doi: 10.1016/j.jcin.2014.02.017, indexed in Pubmed: 25234682.

10. Abellas-Sequeiros RA, Ocaranza-Sanchez R, Galvão Braga C, et al. "Assessment of effectiveness and security in high pressure postdilatation of bioresorbable vascular scaffolds during percutaneous coronary intervention. Study in a contemporary, non-selected cohort of Spanish patients". Int J Cardiol. 2016; 219: 264-270, doi: 10.1016/j.ijcard.2016.06.029, indexed in Pubmed: 27343418.

11. Onuma Y, Serruys PW, Ormiston JA, et al. Three-year results of clinical follow-up after a bioresorbable everolimus-eluting scaffold in patients with de novo coronary artery disease: the ABSORB trial. EuroIntervention. 2010; 6(4): 447-453, doi: 10.4244/ EIJ30V6I4A76, indexed in Pubmed: 20884431.

12. Gori T, Schulz E, Hink U, et al. Early outcome after implantation of Absorb bioresorbable drug-eluting scaffolds in patients with acute coronary syndromes. EuroIntervention. 2014; 9(9): 1036-1041, doi: 10.4244/EIJV9I9A176, indexed in Pubmed: 23999237.

13. Serruys PW, Chevalier B, Sotomi Y, et al. Comparison of an everolimus-eluting bioresorbable scaffold with an everolimuseluting metallic stent for the treatment of coronary artery stenosis (ABSORB II): a 3 year, randomised, controlled, single-blind, multicentre clinical trial. Lancet. 2016; 388(10059): 2479-2491, doi: 10.1016/S0140-6736(16)32050-5, indexed in Pubmed: 27806897.

14. Kajiya T, Liang M, Sharma RK, et al. Everolimus-eluting bioresorbable vascular scaffold (BVS) implantation in patients with ST-segment elevation myocardial infarction (STEMI). EuroIntervention. 2013; 9(4): 501-504, doi: 10.4244/EIJV9I4A80, indexed in Pubmed: 23687101. 